\title{
TaskForce Tarmed
}

Momentan laufen die Arbeiten an der Gesamtrevision des Tarmed-Tarifs mit Hochdruck weiter. Die Subgruppe Ultraschall ist ebenfalls in diese Arbeiten eingebunden. Die neue Nomenklatur steht, mittels eines Pilottests wird deren Tauglichkeit geprüft. Anschließend müssen auch Minutagen und Regeln bereinigt werden. Ende Jahr soll der revidierte Tarif erstellt sein.

\section{Beat Dubs}

Leiter TaskForce Tarmed 